EXPLORING K-3 TEACHERS'

\title{
IMPLEMENTATION OF COMPREHENSION
}

STRATEGY INSTRUCTION (CSI) USING EXPECTANCY-VALUE THEORY

Laura S. Foley

Utah State University

laura.foley@usu.edu 


\begin{abstract}
This research investigated factors that influence the implementation levels of evidencebased comprehension strategy instruction (CSI) among K-3 teachers. An explanatory design was chosen to gather and probe the data. Quantitative data were gathered via mailed surveys distributed through a representative sample of the 40 school districts (through a stratified-random selection of teachers) in a state in the Rocky Mountain West. Expectancy-value theory was applied as it affects self-reported levels of teacher implementation of CSI. Both expectancy and value showed significance for predicting self-reported CSI implementation in two multiple regression analyses. Surveys revealed teachers' perceptions of what impedes or supports their sustained implementation of CSI. These findings suggest that increases in school support will also raise teacher CSI implementation levels.
\end{abstract}


As a primary grade teacher for 22 years, I shared teachers' frustrations and experienced many challenges teaching literacy in the primary classroom. Yet at year end, when the growth of the students is most evident, I was amply rewarded. I witnessed greater growth in my students' overall literacy scores by working most diligently on the purpose for reading-comprehension.

Wasserman (2002) reflected on learning as change in the following fashion:

With each new class...I have to teach myself all over again that where we are at the beginning...will be, should be, very different from where we wind up at the end. Isn't that what teaching is about - the expectation that students will have changed in some significant and wonderful ways through what they have learned? (p. 795).

Progress in education has and will always require renewed teachers who have a clear vision, practice right action, and collaborate; who are willing to take risks and teach on the "edge of chaos" (Brown \& Moffett, 1999, p. 24).

Comprehension is the key to higher-level thinking and the hallmark component of literacy acquisition. Smolkin and Donovan (2001) note, "We are convinced that comprehension of text, the single most important ability developed in the elementary school setting, merits schoolwide attention..." (p. 114). In 1978, Durkin documented a dearth of instruction related to comprehension of text in elementary schools. It was popularly assumed by educators that the purpose of literacy in primary grades K-3 was to 'learn to read' and the focus of grade four and up was to 'read to learn' - comprehension would naturally occur as students learned to read.In contrast to this common assumption, researchers such as Palincsar and Brown $(1984 ; 1987)$ showed the need to teach comprehension strategies in their work with struggling upper grade students. More recently, the accepted belief that comprehension instruction is taught after acquisition of decoding automaticity was challenged by the National Reading Panel (NRP) 
Report (2000) and other national reading reports (Reutzel \& Fawson, 2002). These reports call for teaching comprehension concurrently with teaching the alphabetic principle, phonemes, and phonics. I agree with these researchers that traditional educational practices that focus on learning to read, then reading to learn, are ineffective.

Once I discovered the preponderance of agreement in the correlation between teaching strategy combinations for making meaning of text and improved student comprehension, I proceeded to examine the next challenge: sustaining teacher change. I sought to explore the professional development teachers had received in comprehension strategy instruction (CSI), their perceptions of success in that implementation, the support given for implementing the innovations, and the barriers that hampered their success. Specifically, I wondered: Are primary teachers learning the research-based comprehension strategies detailed by the NRP (2000)? Are they aligning their pedagogy with these recommendations in order to meet increasing literacy acquisition challenges in today's society? Are primary teachers receiving sufficient support to overcome barriers to teaching CSI? Therefore, the purpose of my study was to increase understanding of primary teacher expectancies and self-efficacy (confidence for success) to learn and implement CSI, and in doing so, add to existing knowledge about early instruction of oral and reading comprehension strategies.

This study surveyed teacher implementation of strategy instruction for improved comprehension. My inquiry positions teachers, administrators, and teacher educators to better understand current levels of implementation of comprehension strategies and suggests ideas for meeting the challenges of increasing and/or sustaining their use. Improved understandings of teacher perceptions about implementing CSI will provide information for future decision-making 
regarding supports in primary literacy instruction.

\section{Research Related to Comprehension Strategy Instruction (CSI)}

Comprehension strategy instruction (CSI) is defined here as intentionally and explicitly teaching cognitive strategies that readers use to construct meaning while interacting with text. CSI begins with teacher explanation and modeling, then teacher scaffolding, as responsibility is gradually released to the student (Pearson, \& Gallagher, 1983). It can be accomplished in various teacher-guided settings including small groups and whole class instruction. It is taught using text on the instructional level of the student. Strategies include, but are not limited to, (a) using predictions to activate prior knowledge, (b) think-alouds, (c) text structures, (d) mental imagery, (e) summarization, and (f) questioning/clarifying. These strategies occur in different groupings in the research but have shown potential for overcoming difficulties in student comprehension.

Cunningham and Stanovich (1998) found that reading development is delayed for readers who have a combination of deficient decoding skills and lack of guided practice as they confront materials in school. Smolkin and Donovan (2001) contend that a comprehension-acquisition curriculum beginning with the primary grades would ensure that "growth in concepts and vocabulary would occur simultaneously with growth in decoding” (p. 113). Concept and vocabulary growth have been found by researchers to augment early success at reading acquisition. And early success is one key that unlocks a lifetime of literacy (Cunningham \& Stanovich, 1998). This message was seconded by the NRP (2000) in their report.

To address barriers to comprehension, a number of authors (Duke \& Pearson, 2002; Beck \& McKeown, 2001; Reutzel, Smith, \& Fawson, 2005; Pressley et al., 1992; NRP, 2000; Palincsar \& Brown, 1984; Smolkin \& Donovan, 2001) have suggested explicitly teaching to new readers the strategies that are used by successful readers. Specific comprehension strategies have 
been grouped together in various combinations for instruction under different names by different researchers. They overlap and build upon each other. For example, each uses question-answer relationships (QARs) before, during, and/or after reading (Duke \& Pearson, 2002; Durkin, 1978). In 2002, Duke and Pearson summarized three combinations of QAR strategies that have shown beneficial results in interactive student-text-teacher discourse. Reciprocal teaching (Palincsar \& Brown, 1984; 1987) combines prediction, clarifying, questioning, and summarizing in teacher/student discourse of text. Questioning the author (Beck, McKeown, Sandora, \& Kucan, 1996) is an approach that teaches students to collaboratively ask questions of the author as they tackle the text section by section. Transactional strategy instruction (Pressley et al., 1994; Pressley et al., 1992; Reutzel et al., 2005; Stahl, 2004) adds three components to the reciprocal teaching model: 1) analyses of text structures, 2) thinking aloud, and 3) constructing mental images.

These three similar, yet different, multiple-strategy methods provide evidence-based models for guiding conversations using higher-level thinking surrounding text. Reutzel and Smith (2004) assert: "Explicit teacher modeling and scaffolding of reading skills, thinking processes, and reading dispositions [are] uniformly recognized as a critical part of helping all children learn to read-especially those students who struggle" ( p. 81). The exact strategy taught seems less important than the purposive engagement and text interaction a strategy induces in the learner (Snow, 2001).

To sum up the research on comprehension strategy instruction, not only do frameworks exist that detail the explicit instruction of comprehension strategies but they are supported by a large body of research over the past two decades (Beck et al., 1996; Duffy et al., 1987; NRP, 2000; Palincsar \& Brown, 1984; Smolkin \& Donovan, 2001; Snow, 2001; Snow et al., 1998). 
After analyzing strategies common to the frameworks in the literature, I chose to question teachers about nine individual strategies (see Table 1) related to comprehension instruction. I deduced that I would ask teachers to respond to strategies individually, rather than in their research frameworks, due to an indeterminable number of possible combinations of teacher practice surrounding comprehension pedagogy. Two of the nine strategies I chose (i.e., predictions, prior knowledge) have not been researched individually with significant results. In a study of children with learning disabilities by Joffe, Cain, \& Maric (2007) a third strategy called mental imagery has shown some success for improving the meaning-making of emergent readers, . However, more research is needed in this domain to determine effectiveness of mental imagery on both listening and reading comprehension. Nevertheless, because prediction, accessing prior knowledge, and mental imagery are popularly used with teachers, and because they are included in the multiple-strategy studies, I felt that they merited inclusion in my survey as practice-based pedagogies.

My investigation into the literature on strategy instruction garnered evidence for its importance for improving the comprehension of students. In the next section I discuss a theoretical framework for examining what motivates teachers to put successful pedagogy in practice..

\section{Theoretical Framework: Expectancy-Value Theory and Motivation}

Since motivation is a critical element associated with implementation of pedagogy, I used self-efficacy as a lens for assessing reasons for success or failure behind pedagogy (Rosenthal, 1991). "Self-efficacy, in particular, has produced a seemingly important variable that serves to contribute to overall teacher motivation" (Goker, 2006 p. 242).

"Perceived self-efficacy is defined as people's beliefs about their capabilities to produce 
designated levels of performance that exercise influence over events that affect their lives" (Bandura, 1994 p. 1). Then self-efficacy, also defined as the willingness to attempt a task, is a factor in motivation theories in general (Pressley, 1995). Bandura, Barbaranelli, Caprara, and Pastorelli (1996) define self-efficacy as "Beliefs in one's capabilities to organize and execute the courses of action required to produce given attainments" (p. 3). Each of these definitions builds upon Vroom's (1964) original and classic expectancy model of work motivation. He defined motivation as the product of the perceived likelihood that a behavior will produce an outcome and the anticipated satisfaction of this outcome. So, the willingness of people to attempt a task relies heavily upon their belief that they will successfully complete the task (Bandura, 1993).

From these definitions the relationship between self-efficacy and Vroom's theory can be established. Pressley (1995) agreed that self-efficacy is especially relevant to 'expectancy' in expectancy-value theory. In addition, Bandura and Locke (2003) explained the necessity of adding self-efficacy to expectancy theory to predict achievement. This is because shifts in selfefficacy are likely to cause changes in expectations, which produce changes in performance (Schunk, 1989). Bandura and Locke also asserted that "the predictiveness of expectancy-value theory is enhanced by including the self-efficacy determinant” (p. 88). In light of these connections, and because expectancy measures are enhanced by including self-efficacy determinants to predict achievement (Bandura \& Locke, 2003); I chose to examine teacher efficacies through expectancy-value theory. My choice was also influenced by Abrami, Poulsen, and Chambers (2004) who used expectancy-value theory to explore teacher implementation of a classroom pedagogy called cooperative learning (CL). I see this theory as equally salient to researching teacher implementation of CSI.

My explanation of this motivation theory thus far has focused on the first word, or 
'expectancy' and its relationship to self-efficacy. The second word, 'value,' in expectancy-value theory provides another important factor in recognized motivation theories (Abrami et al., 2004; Bandura and Locke, 2003). Teachers must value a specific method before they will give it their attention and time. They must see their efforts on the task as valuable. Hence, I selected expectancy-value theory to provide a clear way to analyze the factors associated with the degree of teacher implementation of CSI.

In summation, expectancy-value theory explains human behavior as a function of two factors: (a) the perceived value of the reward that certain behavior yields and (b) the expectation in the doer that "certain behavior will actually yield that reward" (Quick, 1988 p. 30). I believe that the results of such research have the potential to posit correlations to inform educational leaders about ways to enhance the future expectancies of success in teachers. The rationale would be expressly to motivate teachers in implementing and maintaining researched-based practices for enhancing comprehension in the early grades (Ohlhausen, Meyerson, \& Sexton, 1992). Hence, I built my research upon a model previously and successfully utilized by Abrami et al. (2004).

In their study Abrami et al. (2004) were able to explore the correlation between teacher motivation via the expectancy-value model and self-reported use of cooperative learning. From their results they developed a heuristic of simple teacher motivation: (expectancy) $+($ value $)-$ $(\operatorname{cost})=$ implementation of an innovation. They incorporated expectancy, value, and cost into the design of their survey items. Value items included the perceived benefits of the innovation to the teacher such as congruence with teaching philosophy, career advancement, as well as the benefits to the students such as increased achievement, and improved attitudes. Next Abrami and colleagues subtracted cost, or available psychological and physical resources, to determine 
whether perceptions of high expenses in time, effort, or money significantly deter teachers' implementation decisions. They found time to be the only significant cost that predicted levels of CL implementation. Expectancy, as defined in terms of self-efficacy, remained the strongest predictor of implementation. Value was next.

In alignment with additional research by (Ebmeier, 2003; Ishler, Johnson, \& Johnson, 1998; Shah \& Higgins, 1997; Parker \& Partridge, 1991), I examined the social aspects of school support, such as perceived levels of CSI training in professional development and other administrative supports, which may affect the efficacies of teachers to implement CSI.

In review, my research incorporated expectancy-value theory in the literature as a framework for examining implementation of CSI. For the purposes of this study, teacher reports on expectancy, value, and cost were correlated with implementation levels of CSI similar to the way Abrami and colleagues (2004) used expectancy-value theory to predict implementation of cooperative learning.

\section{Methodology}

Inservice teachers are in a position to answer questions about their current practices and their levels of implementation of CSI. Therefore, assessing teachers' views and experiences provided important information for understanding current levels of implementation of CSI in grades K-3 and the challenges to that implementation. I gathered data via a survey on teacher perceptions to better understand the extent to which research-based and commonly accepted comprehension strategies have transferred into practice in primary classrooms. The research questions in this study as sought through self-reports are: a) to what extent are primary teachers K-3 using CSI in their classrooms? b) to what extent do teacher efficacies in expectancy, value, and cost surrounding CSI predict their perceived implementation levels of CSI? 
Quantitative data were gathered by surveying teachers of early literacy, grades K-3, from selected school districts regarding nine comprehension strategies (prior knowledge, predicting, questioning/clarifying, reorganizing text, summarizing, stating a purpose, text structures, fix-up strategies, mental imagery) and two delivery strategies (modeling and scaffolding--see Table 1). This study is a model for the use of quota sampling for representation and randomized selection within stratifications and shows that such randomization can be accomplished in education research (see Tables 2 and 3).

\section{Participants}

The participants were teachers employed in grades K-3 in a state in the Rocky Mountain West. I determined a number proportionate to each district K-3 teacher population and added them together to achieve a distribution size calculated to reach reliability with a $40 \%$ return rate. Teachers from each of four grade levels, kindergarten through third grade (and special education teachers assigned to these grades), were randomly selected to receive the survey (see Table 4). The number of surveys distributed was 400, and the number returned was 197 . The 197 responses (a $49.25 \%$ return rate) were more than sufficient to establish power.

\section{Instrument Development}

I modeled the Comprehension Strategy Instruction Questionnaire (CSIQ) on the same scale as the CL survey by Abrami et al. (2004). In the main survey section I designed thirty-four items to assess three main components of expectancy-value theory that have been used in previous studies and may influence the teacher efficacy factors: value, expectancy, and cost. The statements were categorized by component. Items were balanced by phrasing them both positively and negatively to avoid biasing the participants towards an assumed correct response and to assess the span of attitudes toward each component. The content of the items was rated by 
teachers on a five-point Likert scale $(1=$ strongly disagree to $5=$ strongly agree $)$. For examples of subcategories related to expectancy, value, and cost statements in the survey (see Table 5).

Other survey sections included questions on teacher demographics (see Tables 4 and 6), specific training and implementation of CSI, and general teacher implementation of CSI. I designed the CSI training and implementation section of the survey to assess levels of teacher training and also to evaluate teacher frequency of implementation. Training data were gathered to assess the strength of teacher knowledge of CSI. To promote clarity for the researcher and the participants in this section of the survey, frequency of implementation for each strategy was assessed specifically. General teacher implementation of comprehension strategies was assessed in the final survey section. Items here asked teachers for their levels of CSI implementation overall on a Likert-like scale from $5=$ 'almost all of the time' to $1=$ 'not at all' (see Table 7). Survey items were reviewed by two survey development experts and piloted with three teachers. The instrument was refined based on data received during the review and the pilot. I eliminated redundant items and changed the polarity of some items to avoid skewed responses (see Table 5).

\section{Procedures}

The revised instrument was distributed in the fall of 2005 to K-3 teachers from a random sample of districts in a state in the Rocky Mountain West. In order to obtain a representative sample, quota sampling was used. The proportion of surveys distributed to teachers at each grade level matched the proportions of teachers in each grade level as indicated by the district FTEs. Surveys were then randomly distributed via postal services to the selected districts. At the district level, teachers were selected from each grade level K-3 using a randomized number list. The surveys were distributed, then completed and returned voluntarily. 
Pseudonyms replace the actual district names in Table 2. Of the total sample, $N=197$, $58.9 \%(n=116)$ came from large districts, $20.8 \%(n=41)$ from medium districts, and $20.3 \%(n$ $=40)$ from districts in the small category $(S D=0.80$; error of the mean $=.046)$. These figures are roughly representative of the percentage of the state's K-3 and primary special education FTEs: large $=72 \%$, medium $=14 \%$, and small $=14 \%($ see Table 3$)$.

\section{Data Analyses}

With the help of J. Fargo (personal communication, April 17, 2006), a fellow researcher at Utah State University, I assessed the internal consistency reliability of the instrument by calculating a Cronbach's alpha coefficient for scores from each subscale or factor as well as for the total survey instrument. We then evaluated the construct validity of the survey instrument in a confirmatory factor analysis (CFA). Next, we summed the scores from the items within the expectancy, value, and cost factors if the results of the factor analyses indicated that the items significantly loaded onto the latent or scaled factors (Pett, Lackey, \& Sullivan, 2003).

Significance was established using values at $r^{2} \geq .2$. We computed the descriptive statistics for each survey item and for each survey factor. Scores on the implementation statements were then averaged to yield a single score for levels of teacher implementation by specific comprehension strategy and another score for levels of teacher general implementation. From these processes, five latent or scaled factors were established to be used in a multiple regression analyses (Schumacker, \& Lomax, 2004): (a) expectancy, (b) value, (c) cost, (d) specific implementation, and (e) general implementation.

\section{Extent of CSI Use}

To address research question one I computed the descriptive statistics on the data gathered from the Training Background section of the Comprehension Strategy Instruction 
Questionnaire (CSIQ). I interpreted these statistics as descriptive information and no hypotheses were tested. However, I used demographic information such as age, grade level experience, and class size to look at variation in teachers across demographic variables.

\section{Teacher Efficacies and Implementation of CSI}

To address research question two, J. Fargo (June 21, 2006) and I conducted multiple regression analyses using the data gathered from the belief and implementation items on the CSIQ. Next, I conducted a confirmatory factor analysis on the CSIQ for construct validity. Teacher reported levels of implementation on the survey constituted the outcome variable; and expectancy, value, and cost were predictor variables. Training and selected demographic variables served as moderator variables. Demographic and training variables were included in the multiple regressions in order to adjust for differences in teacher characteristics (e.g., grade level experience). A sample size analysis indicated that a sample of 180 provided $80 \%$ power to detect an effect size of $r^{2}=.10$ with up to 12 covariates or moderator variables included in the model, given $\alpha=.05$. This effect size was established as sufficient power by previous research on expectancy and instructional implementations (Abrami et al., 2004).

\section{Findings and Interpretations}

\section{CSIQ Instrument Internal Reliability}

The Cronbach's alpha on the total instrument was 90 (see Table 8). I placed survey items on belief and implementation in separate sections and these items became the scaled variables with some adjustments from the CFA. Each section had an alpha $>.800$ until the belief items were divided by expectancy, value, and cost. Then, expectancy and value alphas were .794 and .785 respectively. The alpha for cost was much lower (.564), perhaps revealing respondent ambivalence over unclear item wording. 


\section{Descriptive Statistics for Research Question One}

Research question 1: As shown through self-reports, to what extent are primary teachers, K-3 using comprehension strategy instruction (CSI) in their classrooms?

Two sections of the CSIQ probed teacher implementation of CSI (see Foley, 2006 for full survey). Section two asked for implementation frequency by individual strategy in order to gather data specific to each. Items in section four were designed to acquire data from teachers about their general practices that are necessary for successful comprehension instruction according to research (Duke and Pearson, 2002; Reutzel \& Fawson, 2002; Beck \& McKeown, 2001; NPR, 2000; Hiebert, Pearson, Taylor, Richardson, \& Paris, 1998; Pearson, \& Gallagher, 1983).

Reported frequency of implementation by strategy and strategy scaled scores. The level of implementation of nine comprehension strategies (prior knowledge, predicting, questioning/clarifying, reorganizing text, summarizing, stating a purpose, text structures, fix-up strategies, mental imagery) and two delivery strategies (modeling and scaffolding) were examined (see Table 1). Means for prior knowledge, predicting, questioning/clarifying, summarizing, using fix-up strategies, and scaffolding were over $4.00(S D<1)$, indicating that teachers implement them more often than weekly, with their use of activating prior knowledge rounding up to almost daily. The lowest response in this more-than-weekly category was for summarizing. The means for the rest of the strategies (i.e., reorganizing text, stating a purpose, using text structures, mental imagery, and modeling) fell into a more-than-every two weeks category, with the latter two strategies rounding up to almost weekly. Nevertheless, the standard deviations for the means of these two items were higher than the other strategies at respectively 1.17 and 1.28. Reorganizing text was the strategy taught least often but still averaged slightly 
more than every two weeks. None of the means for any strategy was less often than every two weeks (see Table 1).

Primary teachers are clearly using CSI. Thirty-two percent of those sampled report using strategies more often than weekly to almost daily and $52 \%$ used strategies twice a week to weekly. Only 28 respondents, or 14\%, reported using strategies less often than every two weeks. One percent reported they used no strategies and $1 \%$ left the section blank (see Table 9).

Reported general implementation rates. In the fourth and final section of the CSIQ, participants reported their general levels of implementation on a different scale of 1 to $5(1=$ Not at all, $2=$ Occasionally, $3=$ About half of the time, $4=$ Most of the time, $5=$ Almost all of the time). There were eight items (35-42) designed to probe the construct. Six of these items remained after the CFA (see Table 7).

The overall mean for the general implementation scale was 29.873. The mean for the six items that showed significance was 3.734 , which rounds up to 4.00 or "most of the time" for implementation rates. Teacher ratings ranged from more than half of the time on "the extent to which you implement CSI in order to motivate students" to a high of most of the time on "the extent to which CSI should be integrated into the reading program" (see Table 7).

Findings and Interpretations for Research Question Two

Research question two: As shown through self-reports, to what extent do teacher efficacies in expectancy, value, and cost surrounding comprehension strategy instruction (CSI) predict their implementation levels of CSI?

Again with the help of J. Fargo (personal communication, June 12, 2006), I conducted two multiple regression analyses from the data gathered by the belief items and implementation items in section three of the CSIQ to address research question two. Specific and general 
implementation levels assessed in sections two and four were the dependent variables.

Expectancy, value, cost, training, and selected demographic variables served as independent variables. Demographic and training variables were included in the multiple regressions in order to adjust for differences in teacher characteristics (e.g., grade-level experience). Several steps were taken to prepare for the regression analyses (see Table 10). We re-examined the reliabilities for the expectancy, value, cost, specific, and general implementation (see Table 11).

Multiple regression 1 and interpretations. We ran the first multiple regression with the specific implementation latent variable as the outcome variable, 12 observed variables, and three scaled variables as independent variables. We used various variable selection strategies to find the best-fitting regression model. First, a simultaneous regression with specific implementation as the dependent variable was run. Low loading items $\left(r^{2}<.2\right)$ were removed in stages. The first result for this MR was $R^{2}=.32$ (see Table 10).

According to section two of the CSIQ (Foley, 2006), teachers' value and expectancy beliefs predict their specific CSI implementation levels. A third predictor of reported teacher implementation of specific strategies was demographic in nature: the reported frequency of school support.

Therefore, three factors showed significance for predicting the implementation of specific comprehension strategies and delivery methods, at an effect size of $r^{2}=.26$ : (a) school support (b) expectancy, and (c) value. The regression equation with these measures was significant, $R^{2}=$ .26 , adjusted $R^{2}=.24, F(4,157)=13.28, p<.01$. See Table 12 for coefficients on the specific implementation analysis. I make the following assertions based upon the regression analysis conducted with specific strategy implementation as the dependent variable. The subtracted variable, cost, was not found to be a significant factor in predicting implementation levels of 
specific strategies.

Frequency of school support predicts implementation levels. The reported frequency of school support correlates with the reported implementation levels of specific comprehension strategies. Perhaps as teachers have an environment with the necessary materials, professional development, collaboration, and support staff such as literacy coaches; their collective efficacies increase to implement curricula that they value.

Teachers' expectancy levels predict their implementation levels. The teachers' expectancy of success for the implementation of a specific comprehension strategy, such as clarifying, and its associated delivery methods, such as modeling and scaffolding student independent practice, correlated positively with their reported implementation level of that strategy. Such positive results add to the research findings that suggest raising teacher expectancies may serve to increase motivation to change and sustain practice (Goker, 2006; Parker \& Partridge, 1991).

Teachers' value levels predict their implementation levels. The value teachers placed on CSI correlated positively with their reported implementation levels of specific comprehension strategies. Again, value results in this study add to the literature that suggests raising values correlates with increases in motivation (Bandura \& Locke, 2003; Ishler, Johnson, \& Johnson, 1998; Shah \& Higgins, 1997). In this case, the higher one values CSI, the higher the motivation to implement CSI.

Multiple regression 2 and interpretations. J. Fargo (June 21, 2006) and I ran the second regression analysis with the general implementation variable as the outcome variable. The general implementation variable data came from the responses to questions in section four of the CSIQ. Of the same twelve observed variables, and three scaled variables that served as 
independent variables, five variables showed significance for predicting teacher implementation of the general methods used in the survey at an effect size of $R^{2}=.43$, adjusted $R^{2}=.39$ : (a) new masters vs. old bachelors, (b) grade level, (c) years in grade (standardized beta weight rises .148 for every year of experience, std error $=.006, t=2.13, p<.05)$, (d) expectancy, and (e) value. The regression $R^{2}=.43$ and adjusted $R^{2}=.39, p<.01$. See Table 13 for coefficients on the general implementation analysis. However, endorsement level 1 was negatively associated at $\mathrm{B}=$ -.244 , std B $=-.156, \mathrm{p}<.05$ and level 2 was not significant. I decided to revisit the data and found that it was entered in the same column as undergraduate reading instruction credits which confused the results. Therefore, the effects of reading endorsements were not used to draw any conclusions. Five variables remained in the regression (see Tables 10 and 13).

Therefore, we found three demographic variables, education, grade level, and years in grade level; and two belief variables, value, and expectancy, to significantly predict general implementation of CSI. I derive and explain five interpretations from the MR2 findings in the next section.

Recent masters in education versus older bachelors degree. Teachers with recent (in or after 2002) masters degrees in education reported significantly higher levels of general implementation than teachers with bachelor's degrees earned prior to 2002 . This is likely due to the recency of their training or the fact that they learned about the importance of and strategies for implementing CSI in the master of education programs.

Grade level factors influencing general implementation. Third grade teachers' means of reported general implementation of CSI were significantly higher than the general mean. General implementation levels of CSI rose as the grade level increased, and, therefore, results point to greater implementation of CSI as children's age and teacher beliefs about student ability to 
decode increase (Reutzel \& Sabey, 1996). It makes sense that younger students are less independent and require more management. It also follows, as Snow and associates (1998) found, that early readers are using additional cognitive reserves than more independent readers when they lack automaticity with the alphabetic principle as they grapple to decode text. Due to the greater demands put upon emergent readers' mental capacities, comprehension of text must be scaffolded or talked about by proficient readers (Beck \& McKeown, 2001). Therefore, it is reasonable to conclude that CSI implementation would increase as the age and independence of the students increase.

The number of years of experience acquired teaching current grade level. Teachers' general implementation of CSI increases as they accrue years of experience in a grade level. This unforeseen result may be explained in terms of teacher experience and improved automaticity. In other words, the longer teachers experience one grade level, the more automatic they become in planning for and handling the array of student needs and classroom demands. The greater their automaticity with student management and the required curricula, the more likely it is that they will be motivated to try something new and challenging. Automaticity and cognitive capacity may apply to teacher learning the same way they apply to reading acquisition.

Expectancy significantly influences general implementation rates. Reported expectancy correlated positively with reported implementation of CSI constructs in general. Raising teacher expectancy levels may serve to increase the supportive constructs that surround successful CSI, such as consistent time allotments, small group instruction, and progress monitoring.

Value significantly influences general implementation rates. The reported value correlated positively with the reported implementation of CSI constructs in general. This result mirrors the one for expectancy. The value teachers place on a given pedagogy may predict their 
motivation to implement it. Getting teacher 'buy-in' is a common way to express this concept. I believe the results in my study support beginning with teacher buy-in when introducing new instructional methods.

\section{Implications}

The literature shows that there is a relationship between teacher expectancy-value and teacher receptiveness to implementing an innovation (Abrami, 2004; (Bandura \& Locke, 2003; Ishler et al., 1998; Shah \& Higgins, 1997; Rosenthal, 1991). My study adds to this research by demonstrating that a correlation exists between teachers' expectancy-value of CSI and their willingness to implement it. Therefore, the CSIQ could be a powerful instrument for identifying teachers with self-efficacies that reflect a personal expectation to grow and learn in this pedagogy.

In addition, supervisors, school board members, and legislators who wish to increase effective comprehension instruction might work toward modifying school environments to combine as many of the predictors (i.e., school support) found in the regression analyses as possible. The results of this study argue for the use of the CSIQ for better selection of teachers as candidates for professional development in comprehension strategy training. This way, hardfound funding could be used more efficiently to get successful comprehension instruction into the curriculum.

Stakeholders might start with allocating funds for school-based literacy coaches trained in CSI with an emphasis on extra support for kindergarten and first grade teachers who experience the greatest curriculum competition and language learning challenges. Teacher collaboration and study in small groups should be maintained to provide peer support to conquer the steep learning curve (Pressley, 2002; Williams, 2002). 
Questionnaire items on specific comprehension strategies were kept separate in this study in order to maintain clarity for the participants; however, research only supports some of these strategies (i.e., prior knowledge activation and prediction) when applied in combination with others. Therefore, decision-makers must use caution as they make plans to provide specific, intense professional development on CSI. Training should align with the research. Four sets of cognitive strategies that have proven effective for reading comprehension are: (a) transactional strategy instruction (Pressley et al., 1994; Reutzel et al., 2005), (b) direct instruction (Duffy et al., 1987), (c) reciprocal teaching (Palincsar \& Brown, 1984), and (d) questioning the author (Beck et al., 1996).

The teachers studied were using CSI to varying extents. The vast majority of these K-3 teachers reported some exposure to CSI and some reported being well-trained. Concurrently, the mean responses show more-than-weekly implementation of five of the nine strategies polled (prior knowledge, predicting, questioning/clarifying, summarizing, using fix-up strategies—see Table 1). Whether or not this frequency is sufficient implementation is unclear. However,these results serve to answer in part the extent to which K-3 teachers are using CSI in their classrooms. The modest results, while marking improvements over the suggestions of past research, warrant the continued and renewed efforts of decision-makers to raise the levels of teacher implementation of this complex pedagogy.

According to the second regression, results indicate that decision-makers might encourage teacher longevity in a grade level for 8 years or more. General CSI implementation was positively correlated with the number of years teaching the same grade level. Those teachers who were struggling the most with consistent CSI implementation had taught for the fewest number of years in their respective grades. 
Through the development of the CSIQ and two regression analyses, this study successfully used expectancy-value theory to predict CSI implementation in the classroom. Results indicate that those who value using the strategies to teach comprehension, and anticipate implementing them with success, report higher levels of implementation. The efforts of decisionmakers to raise teacher efficacies in CSI through specific increases in school support should also raise implementation levels of CSI. However, sustaining teacher implementation poses a further challenge.

There are several examples in the literature with suggestions for sustaining teacher change that may be examined (Fullan, 1991). For instance, in recent research Intrator and Kunzman (2006) advocated "multi-level learning" to raise teacher beliefs. Their work provides a way to raise both value and expectancy. Their method for multi-level learning invites teacher renewal by focusing on support for intensive reflection on teaching practice (Goker, 2006; Ferraro, 2000), shared purposes, and specific coaching (Showers \& Joyce, 1996). These foci would serve to foster teacher growth and capacities before requiring engagement in "pedagogy, content, and policy" (p. 4). As teachers collaborate and are given control over implementing a specific method, their change in attitude toward that task may profoundly affect their success in much the same way that attitude affects general teacher efforts (de Jesus, 2005; Parker \& Partridge, 1991; Wright, 1985). Reflective practice sustains effective pedagogy.

My CSIQ analyses support the advocacy of greater supports for teachers to learn and engage in pedagogies new to them. In addition, in the qualitative portion of my research on CSI, interviewees mentioned school-based literacy coaches as one form of support they had either experienced or would like to experience. In this (unreported) portion of my research I analyzed the reported positioning (the accessibility and length of service) of literacy coaches with the 
survey data. Coaching emerged as an over-riding determinant that distinguished the experiences of high CSI implementers from moderate implementers (Foley, 2006). But that is the topic of another article. I would like to suggest a plan of action for educational reform that decisionmakers may initiate and which is supported by this research along with others cited herein.

Administrators might consider using the survey to identify candidates for professional development. Then they would choose a series of professional development that focuses on one of the research-based, multiple strategy forms of comprehension instruction. During and after the training series, teacher candidates would be given additional support in their classrooms as they grapple with the new pedagogy. Follow-up training sessions would be provided as indicated by their feedback along with feedback from teacher-leaders and student comprehension assessments. These forms of school-based research are often referred to as action research in the literature (ALPS, 2006). Similarly, action research could be conducted on the school data from the training and observations of literacy coaches. Where formal coaching is not available, teachers and leaders could form peer-coaching teams to sustain new pedagogy.

I believe these steps would serve to raise teacher competencies and confidences which will raise their value and expectancies for CSI. And the value and expectation for success that teachers possess for a given pedagogy predict their motivation to implement this evidence-based practice.

Regardless of the format of CSI chosen, sustained support nurtures new and complex pedagogy (Gersten, Chard, \& Baker, 2000; Fullan, 1991). As student assessment results improve, further teacher collaboration will give additional teachers in the school community access to research-based practices in CSI. Finally, reflection on successes through teacher observations and assessment measures will determine the next CSI training needs and the process begins 
again.

\section{Limitations and Directions for Future Research}

Methodological issues inherent in this investigation suggest the need for additional research to extend the findings. Findings in this study regarding CSI implementation levels of K3 teachers overall are encouraging. Nevertheless, participants may have overstated or misrepresented their actual feelings and practices in the surveys. Other forms of research, such as classroom observation, can increase the authority of the major findings and offer additional support.

Due to a low number of participants per survey item (about five per item), the findings are also limited. The required 10-15 participants-per-item for the confirmatory factor analysis was not met. Future investigations should attempt to either reduce the number of independent variables or include sufficient numbers of teachers per survey item by increasing the sample or limiting the questions. Still, the sample was random and the sample size was sufficient to meet effect size requirements (see Tables 4 and 14). This study used quota sampling for representation and randomized selection within stratifications. Future education surveys might follow this procedure which is less common in current educational research practices.

The results did not address the issue of how much comprehension strategy instruction is enough. The highest response on the 1-5 scale of implementation was 'almost daily.' The highest means of summed results by comprehension strategy were between 'weekly' and 'almost daily' indicating a range from 2 to 5 days a week. Two days of CSI per week on any one strategy would not be sufficient for optimum learning according to Reutzel et al. (2005). This research, comparing transactional strategy instruction with single strategy instruction, argues for multiple strategy instruction provided at least 3 days per week. 
The data here-in also do not clarify if teachers are teaching one or more strategies per week singly, or in combinations. One general implementation item on the survey does clarify that on average teachers implement CSI 20-minutes a day "most of the time" as shown by a mean on 185 responses of 3.73 and a median of 4.0. In contrast, the research by Reutzel and colleagues (2005) used 35 to 40 minute lessons with second graders. Future survey use for research objectives would require appropriate revisions to the survey in order to address these clarification issues.

Another issue that needs illumination concerns just what constitutes school support. While the overall responses on levels of school support for CSI were positively correlated with implementation in the CSIQ, there were only two general questions probed by the Likert scale., However, school support has been shown to be significant for teacher efficacy in another study by Ebmeier (2003) that surveyed a larger range of teachers (K-12) from 200 school districts Ebmeier details what supervision practices impact teachers' commitment and efficacy levels in general, though he admits that the paths of influence are complex and indirect. More research is warranted to document the types of supervisory action that will support teacher efficacies surrounding instruction of comprehension strategies.

The results of this study suggest that teachers have made some progress in the amount of time dedicated to comprehension instruction in comparison with the teacher and classroom observations made by Durkin in 1978 (also 1981). However, survey data rely upon reports and cannot fairly compare with the results of an observational approach. Therefore, future research that includes classroom observation of teacher implementation of comprehension strategy instruction would confirm this suggestion. 


\section{Conclusion}

As comprehension is key to deeper learning and as classroom teachers of early literacy are required to incorporate comprehension strategy instruction (CSI) into their pedagogy, then CSI must first be seen as valuable and also be seen as doable (Ohlhausen, Meyerson, \& Sexton, 1992). I add my research on the implementation of CSI to the literature on teacher efficacy for learning and implementing new pedagogies. The result of my inquiry positions teachers, administrators, and teacher educators to better understand recent levels of teacher implementation of CSI and suggests ideas regarding professional development for meeting the challenges of increasing and/or sustaining their use.

As educators, it is my hope that we have the courage to negotiate the inherent chaos of the learning curve that comes with the execution of research-based practices. Only through our own learning, and acting upon that learning, can we approach our goals for our students. Then, at the end of the year, we will realize the significant differences in student learning that we blissfully imagined on the first day of class. Isn't this why we teach? 


\section{References}

Abrami, P. C., Poulsen, C., \& Chambers, B. (2004). Teacher motivation to implement an educational innovation: Factors differentiating users and non-users of cooperative learning. Educational Psychology, 24(2), 201-217.

Active learning practice for schools (ALPS): Teaching for understanding. ALPS a website of Harvard Graduate School accessed July 31, 2006 from http://learnweb.harvard.edu/ALPS/tfu/index.cfm

Bandura, A. (1993). Perceived self-efficacy in cognitive development and functioning. Educational Psychologist, 28(2), 117-149.

Bandura, A. (1994). Self-efficacy. In V. S. Ramachaudran (Ed.), Encyclopedia of human behavior (Vol. 4, pp. 71-81). New York: Academic Press. (Reprinted in H. Friedman [Ed.], Encyclopedia of mental health. San Diego: Academic Press, 1998).

Bandura, A., Barbaranelli, C., Caprara, G, V., \& Pastorelli, C. (1996). Multifaceted impact of self-efficacy beliefs on academic functioning. Child Development, 67(3), 1206-1222.

Bandura, A., \& Locke, E. A. (2003). Negative self-efficacy and goal effects revisited. Journal of Applied Psychology, 88(1), 87-99.

Beck, I. L., \& McKeown, M. G. (2001). Text talk: Capturing the benefits of read-aloud experiences for young children. Reading Teacher, 55(1), 10-21.

Beck, I. L., McKeown, M. G., Sandora, C., \& Kucan, L. (1996). Questioning the author: A yearlong classroom implementation to engage students with text. The Elementary School Journal, 96(4), 385-414.

Brown, J. L., \& Moffett, C. A. (1999). The hero's journey: How educators can transform schools and improve learning. Alexandria, VA: Association for Supervision and Curriculum Development.

Cunningham, A. D., \& Stanovich, K. E. (1998). What reading does for the mind. American Education, 22, 8-15.

de Jesus, S. N. (2005). An integrated model for the study of teacher motivation. Applied Psychology: An International Review, 54(1), 119-134.

Duke, N. K., \& Pearson, P. D. (2002). Effective practices for developing reading comprehension. In A. E. Farstrup \& S. J. Samuels (Eds.), What research has to say about reading instruction ( ${ }^{\text {rd }}$ ed., pp. 205-242). Newark, DE: International Reading Association. 
Duffy, G. G., Roehler, L. R., Sivan, E., Rackliffe, G., Book, C., Meloth, M. S., Vavrus, L. G., Wesselman, R., Putnam, J., \& Bassiri, D. (1987). Effects of explaining the reasoning associated with using reading strategies. Reading Research Quarterly, 22, 347-368.

Durkin, D. (1978). What classroom observations reveal about reading comprehension instruction. Reading Research Quarterly, 14, 481-553.

Durkin, D. (1981). Schools don't teach comprehension. Educational Leadership, 38(6), 453-454.

Ebmeier, H. (2003). How supervision influences teacher efficacy and commitment: An investigation of a path model. Journal of Curriculum and Supervision, 18(2), 110-141.

Ferraro, J. M. (2000). Reflective practice and professional development. [Electronic version]. ERIC Digest, ED449120.

Foley, L. S. (2006). Using expectancy-value theory to explore $k$-3 teachers' self-reported implementation of comprehension strategy instruction. Unpublished doctoral dissertation, Utah State University, Logan, Utah.

Fullan, M. G. (1991). The new meaning of educational change ( $2^{\text {nd }}$ ed.). New York: Teachers College Press.

Gersten, R., Chard, D., \& Baker, S. (2000). Factors enhancing sustained use of research-based instructional practices. Journal of Learning Disabilities, 33(5), 445-457.

Goker, S. D. (2006). Impact of peer coaching on self-efficacy and instructional skills in TEFL teacher education. System, 34(2), 239-254.

Hiebert, E. H., Pearson, P. D., Taylor, B. M., Richardson, V., \& Paris, S. G. (1998). Every child a reader: Applying reading research in the classroom. University of Michigan, Center for the Improvement of Early Reading Achievement (CIERA), Ann Arbor.

Intrator, S. M., \& Kunzman, R. (2006). Starting with the soul. Educational Leadership, 63(6), $38-42$.

Ishler, A. L., Johnson, R. T., \& Johnson, D. W. (1998). Long term effectiveness of a statewide staff development program on cooperative learning. Teaching and Teacher Education, $14(3), 273-281$.

Joffe, V. A., Cain, K. \& Maric, (2007). Comprehension problems in children with specific language impairment: Does mental imagery training help? International Journal of Language \& Communication Disorders, 42(6), p648-664.

National Reading Panel. (2000). Teaching children to read: An evidence-based assessment of the scientific research literature on reading and its implications for reading instruction 
(National Institute of Health Pub. No. 00-4769).Washington, DC: National Institute of Child Health and Human Development.

Ohlhausen, M. M., Meyerson, M. J., \& Sexton, T. (1992). Viewing innovations through the efficacy-based change model: A whole language application. Journal of Reading, 35(7), 536-541.

Palincsar, A. S., \& Brown, A. L. (1984). Reciprocal teaching of comprehension-fostering and comprehension-monitoring activities. Cognition and Instruction, 1(2), 117-175.

Palincsar, A. S., \& Brown, A. L. (1987). Enhancing instructional time through attention to metacognition. Journal of Learning Disabilities, 20(2), 66-75.

Parker, D. R., \& Partridge, R. (1991, June). Expectancy, teacher motivation, and exemplary schools. Paper presented at the Annual Meeting of the Mid-South Educational Research Association, Lexington, KY. (ERIC Document Reproduction Service No. ED341 660)

Pearson, P. D. \& Gallagher, M. C. (1983). The instruction of reading comprehension. Contemporary Educational Psychology, 8, 317-344.

Pett, M. A., Lackey, N. R., \& Sullivan, J. J. (2003). Making sense of factor analysis: The use of factory analysis for instrument development in health care research. Thousand Oaks, CA: Sage.

Pressley, M. (2002). Metacognition and self-regulated comprehension. In A. E. Farstrup \& S. J. Samuels (Eds.), What research has to say about reading instruction $\left(3^{\text {rd }}\right.$ ed., pp. 291309). Newark, DE: International Reading Association.

Pressley, M. (1995). Advanced educational psychology for educators, researchers, and policymakers. New York: Harper College Press.

Pressley, M., El-Dinary, P., Gaskins, I., Schuder, T., Bergman, J., Almasi, J., et al. (1992). Beyond direct explanation: Transactional instruction of reading comprehension strategies. The Elementary School Journal, 92(5), 513-555.

Pressley, M., El-Dinary, P., Brown, R., Schuder, T. L., Pioli, M., Green, K., et al. (1994). Transactional instruction of reading comprehension strategies: Perspectives in reading research no. 5. Athens, GA: National Reading Research Center. (ERIC Document Reproduction Service No. ED 375391).

Quick, T. (1988). Expectancy theory in five simple steps. Training and Development Journal. 42(7): 30-32.

Reutzel, D. R., \& Fawson, P. C. (2002). Changing the face of reading instruction: Recommendations of six national reading reports. Reading Horizons, 42(4), 235-270. 
Reutzel, D. R., \& Sabey, B. L. (1996). Teacher beliefs and children's concepts about reading: are they related? Reading Research and Instruction, 35, 323-342.

Reutzel, D. R., \& Smith, J. A. (2004). Accelerating struggling readers' progress: A comparative analysis of expert opinion and current research recommendations. Reading and Writing Quarterly, 20, 63-89.

Reutzel, D. R., Smith, J. A., \& Fawson, P. C. (2005). An evaluation of two approaches for teaching reading comprehension strategies in the primary years using science information texts. Early Childhood Research Quarterly, 20(3), 276-305.

Rosenthal, R. (1991). Teacher expectancy effects: A brief update 25 years after the Pygmalion Experiment. Journal of Research in Education, 1(1), 3-12.

Schumacker, R. E., \& Lomax, R. G. (2004). A beginner's guide to structural equation modeling ( $2^{\text {nd }}$ edition). Mahwah, NJ: Erlbaum.

Schunk, D. H. (1989, March). Attributions and perceptions of efficacy during self-regulated learning by remedial readers. Paper presented at the Annual Meeting of the American Educational Research Association, San Francisco, CA.

Shah, J., \& Higgins, E. T. (1997). Expectancy X value effects: Regulatory focus as determinant of magnitude and direction. Journal of Personality and Social Psychology, 73(3), 447458.

Showers, B., \& Joyce, B. (1996). The evolution of peer coaching. Educational Leadership, 53(6), 12-17.

Smolkin, L. B., \& Donovan, C. A. (2001). The contexts of comprehension: The information book read aloud, comprehension acquisition, and comprehension instruction in a firstgrade classroom. The Elementary School Journal, 102, 97-121.

Snow, C. E. (2001). Reading for understanding: Toward a research and development program in reading comprehension. Santa Monica, CA: Rand.

Snow, C. E., Burns, M. S., \& Griffin, P. (Eds.). (1998). Preventing reading difficulties in young children. Washington, DC: National Academy Press.

Stahl, K. A. D. (2004). Proof, practice, and promise: Comprehension strategy instruction in the primary grades. The Reading Teacher, 57(7), 598-609.

Vroom, V. H. (1964). Work and motivation. New York: Wiley.

Wasserman, S. (2002). Leaving. Phi Delta Kappan, 83(10), 792-795. 
Williams, J. P. (2002). Reading comprehension strategies and teacher preparation. In A. E. Farstrup \& S. J. Samuels (Eds.), What research has to say about reading instruction $\left(3^{\mathrm{rd}}\right.$ ed., pp. 243-260). Newark, DE: International Reading Association.

Wright, R. (1985). Motivating teacher involvement in professional growth activities. Canadian Administrator, 24(5), 1-6. 